\title{
Costurar o tempo: tessituras para um arquivo nagô
}

\author{
Diego Granja do Amaral' \\ https://orcid/0000-0002-1785-5131 \\ I - Centro Universitário Maurício de Nassau. \\ Recife (PE), Brasil.
}

Resumo: Partindo de um breve exame sobre a questão do arquivo e o mal de arquivo em Derrida ([1995] 2001), este trabalho propõe uma reinterpretação do conceito de arquivo a partir de uma leitura da Arkhé nagô (SODRÉ, 2017) na obra de Rosana Paulino. Como argumento central, defendo a necessidade de se produzir arquivos como espaços de cura e emergência criativa da memória. Com isto em mente, proponho a noção de arquivo nagô em uma discussão que atravessa as manifestações do movimento Black Lives Matter na cidade de Bristol, na Inglaterra, em direção ao trabalho da artista Rosana Paulino, que serve de base para esta proposta. O objetivo é pensar a questão do arquivo no contexto do Brasil contemporâneo e, portanto, desde uma perspectiva não-eurocêntrica.

Palavras-chave: arquivo; memória; Arkhé; Rosana Paulino.

Abstract: Sewing time: weaving a Nagô archive - Upon a brief comment on the notion of archive fever in Derrida ([1995] 2001), this paper proposes a reinterpretation of the issue concerning the archive which builds upon the notion of Arkhé nagô (SODRÉ, 2017) based on the work of Rosana Paulino. As a central argument, I contend for the necessity of producing archives as healing spaces and areas for creative emergence of memory. Bearing this in mind, I propose the notion of nagô archive, a proposition that builds upon an analysis of the Black Lives Matter protests in Bristol and the works of Rosana Paulino, the latter being the central focus of the analysis. The main goal is to discuss the issue of the archive within the context of contemporary Brazil, hence from a non-Eurocentric point of view.

Keywords: archive; memory; Arkhé; Rosana Paulino. 
Exu matou um pássaro ontem com a pedra que atirou hoje. Aforismo nagô

\section{Primeiras impressões}

Em 1994, por ocasião de um colóquio organizado pela Sociedade Internacional de Psiquiatria e da Psicanálise, Derrida realizou uma intervenção intitulada "O conceito de arquivo: uma impressão Freudiana". Abrindo a fala, o filósofo colocou a seguinte questão: "por que reelaborar hoje um conceito de arquivo?" ([1995] 2001, p. 7). Como a costura, a escrita consiste na articulação de pontos sobre um plano e, neste caso, o plano escolhido consistia na leitura de Freud à luz da herança judaica. Não por acaso, Derrida afirma explicitamente ser a questão judaica um dos fios condutores de seu argumento e avalia que "a questão judaica" "atravessa" a psicanálise ([1995] 2001, p.9).

É, pois, partindo da obra de Freud e seu legado que Derrida irá desenvolver sua fala, posteriormente publicada sob o título de Mal de arquivo: uma impressão Freudiana. Mais que uma reflexão sobre a memória, Mal de Arquivo apresenta o entrelaçamento — ou "atravessamento" — da teoria e do pensamento científico pela cultura (judaica). Traça assim as linhas que formam as impressões do judaísmo sobre Freud, da psicanálise sobre Derrida e uma retomada do judaísmo também por este último. São pegadas renovadas por outros caminhos.

Recuperando o vocabulário adotado pelo pensador judeu-franco-magrebino, desejo revisitar impressões deixadas em Mal de arquivo. O objetivo é reelaborar a noção de arquivo sobre outro tecido social. Entre o desvio e a reverência, gostaria de pensar um projeto de reconstrução da noção de arquivo "hoje", desde o Brasil. Afinal, pensar criticamente o conceito de arquivo, a partir de Derrida, exige uma perspectiva historicamente situada (BIRMAN, 2008).

Retomemos, então, o debate sobre o arquivo a partir de sua origem: a palavra grega Arkhé. Revisitando a etimologia do termo, Derrida evoca as ideias de começo e comando, uma concepção "técnica e política, ética e jurídica" (2001, p.8). Em outras palavras, o arquivo se configura como dispositivo e lei. Ainda de acordo com aquele autor, outra característica importante do arquivo seria a de uma memória prostética (hypomnema).

O termo grego referia-se a cadernos de anotação aos quais Platão denomina como uma forma de memória auxiliar. Trata-se, então, de uma extensão da lembrança que extrapola o indivíduo, uma tentativa de suplementação 
da memória biológica. Por tal razão, para Derrida a "potência arquivolítica [...] leva não somente ao esquecimento, à amnésia, à aniquilação da memória" ([1995] 2001, p.22). Para além disso, essa força implicaria, em última instância, em sua própria destruição, a destruição do arquivo. Isto porque, segundo ele, "o arquivo tem lugar em lugar da falta originária e estrutural da chamada memória" ([1995] 2001, p.22).

Essa pulsão destrutiva e anárquica seria uma contradição inerente ao arquivo. Neste ponto, fica especialmente evidente a relevância da "impressão Freudiana" sobre a proposta de Derrida. Uma ideia de arquivo no desejo de uma memória expandida que se estenderia no tempo acumulando-se até o ponto de sua própria destruição. A tendência inevitável à autodestruição, portanto, caracteriza o "mal de arquivo".

No cerne do problema está a distinção entre uma memória "interna" (mneme e anamnese), biológica e uma memória prostética (hypomnema). Localizado no âmbito exterior, o arquivo teria a função de registrar o que escapa às outras formas de memória. Ou seja, arquivo é o aparato criado contra o esquecimento. Igualmente, reconhecer a dimensão propriamente exterior da memória arquivística é uma contribuição de Derrida para o debate em torno do problema. Assim, o autor, ao apontar para "fora", reconhece a dimensão do esquecimento e da renovação como intrínsecos ao processo de arquivamento.

Desta forma, tendo em vista o caráter social da memória, cabe questionar o papel do arquivo em sua dimensão não de suplemento, mas esteio da memória. Como a própria psicanálise irá ensinar, a subjetividade não está desvinculada de relações intersubjetivas e da presença do sujeito no mundo. O esquecimento, sendo constitutivo da memória, é fruto de agenciamentos e modulações do desejo.

Logo, é possível pensar o arquivo não exclusivamente como o lugar de preservação e extensão de uma memória produzida externamente (a ele). Como prótese, o arquivo é vivo e integrado ao organismo a que se associa. Nesse sentido, o caráter prostético do arquivo se revela fundamental para territórios cujas memórias foram amputadas pelos genocídios fundadores da empreitada colonial. Um dispositivo estratégico para a integração de culturas diaspóricas.

Admitindo uma resposta positiva a tais pontos, a questão passa a ser como construir um arquivo capaz de produzir memória e reconhecer esquecimentos. 
Lembrar e esquecer, como sociedade, não são outra coisa senão expressões de uma agenda partilhada. De relações de poder assimétricas expressas nas formas da cidade, dos museus, dos corpos. No cerne dessa discussão, além do direito à lembrança, há a questão anterior a respeito das estruturas e condições para a lembrança e os instrumentos de registro.

Naturalmente, em Derrida há o reconhecimento da importância do arquivo como instituição de preservação da cultura. Seu alerta, contudo, é para o paradoxo gerado pela exterioridade do arquivo. Configurado como um espaço de "consignação da memória", fadado a repetir-se no tempo, o arquivo é capturado pela insistência em uma memória baseada em um princípio normativo. A partir da norma, o arquivo está fadado a repetir a si mesmo. Consequentemente, o princípio gerador do arquivo traz consigo as condições de possibilidade para sua própria destruição. Esse risco remeteria à condição originária do arquivo: a Arkhé (princípio) em seu duplo estatuto de começo, como início, e comando, lei. Estendendo, de forma regrada, um determinado começo no tempo, o arquivo volta-se para si mesmo, não mais responde ao corpo social que Ihe originou. Seria, pois, capturado por uma febre de repetição ao longo do tempo linear. É essa tal febre de repetição do mesmo mal de arquivo.

Ainda que sem mencionar a grega, Achille Mbembe retoma a questão do arquivo como "arquitetura" (lugar) e "documento" (lei/registro/memória), e destaca que o arquivo não é "um dado, mas um status" (2002, p.20). Um status que, segundo ele, parte de uma dimensão material, tátil. Essa materialidade é uma característica fundamental do arquivo pois confirma sua legitimidade como prova. O autor argumenta ainda que o arquivo se organiza a partir de fragmentos que, articulados, contam uma história e criam elos ligando "começo" e "fim" (MBEMBE, 2002, p.21). Não por acaso, o arquivo é um dispositivo chave para o Estado, que vê na "comodificação da memória" a possibilidade de obliterar a "distinção entre vítima e perpetrador, e consequentemente permite ao Estado realizar o que ele sempre sonhou: a abolição do débito e a possibilidade de começar do zero" (MBEMBE, 2002, p.25, grifos meus).

Tendo isto em mente, apontamos para a necessidade de se pensar uma outra potência arquivolítica. Neste ponto, cabe tomarmos uma referência concreta a fim de situar o outro elemento central na nossa formulação, o “hoje”. Essa posição no tempo e espaço exige a constituição de arquivos nutridos a partir 
das bases, negando ao Estado a possibilidade de abolição do débito histórico. Com isto em mente, consideramos como primeiro ponto de referência o caso da estátua do traficante de escravos Edward Colston, arrancada de seu posto e atirada em um rio na cidade de Bristol, na Inglaterra.

De um lado, posições mais conservadoras alegam que ela deveria permanecer onde estava. Segundo o secretário de Estado inglês Pitri Patel, o ato de derrubar a estátua foi "totalmente vergonhoso", e classificou a ação como vandalismo (GOGARTY, 2020, online). Por outro lado, o historiador David Olusoga, argumenta que "a derrubada da estátua não foi um ataque à história. Ela [a ação] foi história" (OLUSOGA, 2020, online).

É sintomático que, no caso de Bristol, em resposta à derrubada da estátua de Colston, tenha sido erguida uma outra imagem, desta vez tendo como modelo Jen Reid, uma mulher de punhos cerrados e levantados no ar. Ainda mais importante é o fato de a estátua ter se baseado no gesto da manifestante após a derrubada da figura anterior. Na imagem afrodiaspórica de Jen, há a presença espectral de Colston. Reproduzindo o punho cerrado dos Panteras Negras, e com uma vestimenta que evoca o estilo do grupo, ela tomou o pedestal, antes tomado pelo comerciante de escravos e, com ela, imagens ancestrais se atualizam. Escravos traficados e beneficiários do tráfico se encontram no pedestal, agora ocupado por uma mulher negra. Erguendo a cabeça e os punhos, Jen ocupou o tempo, inaugurando um novo princípio.

Na ressaca dos protestos em Bristol, outras estátuas em homenagem a figuras emblemáticas do colonialismo europeu foram revisitadas. Em Londres, a estátua do comerciante Robert Milligan foi removida da parte externa do museu da região das docas, na Virgínia, a estátua de Colombo foi jogada em um lago, e em Boston e Connecticut estátuas do mesmo personagem histórico foram decepadas (MEIRELLES, 2020, online). A repetição de gestos simbólicos sugere a reiteração de atos que ressoam uma luta comum contra o colonialismo. Há, no ataque às estátuas, a liberação de uma energia popular que reverte a violência do colonizador contra seus símbolos, e sobretudo, um gesto do povo dirigido às estruturas ainda coloniais do Estado.

O que o caso de Bristol, assim como outros, parece sugerir, é a necessidade de se produzir arquivos a partir da diversidade. Arquivos não centrados na extensão de si mesmos, mas antes, no princípio da heterogeneidade, e na premissa de que princípios são múltiplos e atualizáveis, ainda que para isso seja necessário repensar o arquivo como lugar/instituição. Por outro lado, 
o arquivo é fundamental em sua condição de resposta ao esquecimento, não de repetição exaustiva e ordenada da memória.

Diante dessas proposições, a questão que se coloca a um estudo que pretende pensar a memória a partir da experiência brasileira é: qual ideia de arquivo adequada aos povos marcados pelo colonialismo? Uma noção de arquivo como abundância e repetição em um tempo que, se estendido, daria conta de pensar a herança afro-diaspórica na América crioula (GLISSANT, 2008, p.83)? Supondo uma resposta negativa para essas questões, colocamos, então, a pergunta fundamental: como tratar as impressões do colonialismo na memória coletiva? Tomando essas indagações como pistas, proponho buscar formas de olhar a história, novas formas que permitam organizar o presente de acordo com outro princípio.

\section{Por uma Arkhé nagô}

Abri este texto com o nagô que ensina que Exu matou um pássaro ontem com a pedra que atirou hoje. Evocando essa premissa de um tempo maleável, não linear, Muniz Sodré argumenta que a palavra grega Arkhé deve ser interpretada como princípio (2017). Com essa leitura, Sodré abre uma fresta para a cosmologia nagô na Arkhé. Tal princípio, para Sodré, é constantemente atualizável. Entendemos, então, que uma dessas atualizações da Arkhé nagô se dá no Brasil.

Sobre o tema das migrações formativas da cultura nagô no Brasil, João Dias observa que na "África Ocidental, a simbiose cultural, a bricolagem e aculturação ocorrem a ritmo alucinante" (2013, p.186). É na esteira desse processo "alucinante", dessa simbiose cultural, que propomos uma reflexão sobre a memória e o arquivo como instituição da memória cultural. A exemplo da "filosofia de diáspora" proposta por Sodré (2017, p.40), o arquivo nagô se manifesta na modulação do tempo em seu regime diaspórico. Não se trata, portanto, de uma ruptura, mas de continuidade por outros caminhos.

Assim, a Arkhé recusa o princípio ontológico do "lugar de residência", pois se manifesta no movimento e na condição de um princípio atualizável. A leitura da Arkhé proposta por Sodré é estratégica por duas razões. Primeiro, por retomar o arquivo como multiplicidade, na medida em que discute uma herança presente, viva e complexa. Na obra de Sodré, essa origem não pode ser dissociada da coisa mesma, neste caso, o pensamento nagô presente nas práticas afro-brasileiras. Trata-se de uma origem múltipla, renovável e 
circular. Como destaca Machado referindo-se ao sistema ético e divinatório iorubá do Ifá, “origem não é começo, pois no círculo, no opelê-ifá pode-se começar de vários lugares" (2014, p.115). Seguindo esta mesma tradição, Sodré também não reconhece o tempo como progressão linear. De acordo com essa tradição de pensamento, o tempo é encarnado, tendo no corpo uma dimensão fundamental da temporalidade (SODRÉ, 2017).

Na contramão da metafísica, Sodré propõe um pensamento que começaria "na cozinha" e é mobilizado e modulado pelo corpo (2017, p.36). Sodré, portanto, propõe um pensamento com sabor e textura, ou seja, mediado pela experiência estética. Na construção de seu argumento, o autor alega não "recorrer à suposta certeza dos argumentos de autoridade, mas inscrevendo-os num novo discurso, que visa a uma nova iluminação" (SODRÉ, 2017, p.37, grifos meus). Na própria tessitura desse saber, o autor articula visões do cânone ocidental em uma construção renovada, ou seja, inscreve-se sobre um outro plano epistemológico, outro corpo. Esse exercício, que contribui para abrir caminhos para um pensamento nagô em âmbito acadêmico, desfia a episteme grega em favor de proposições não coloniais da memória. Similarmente, Adilbênia Machado sugere um pensamento “diverso, numa perspectiva horizontal, circular, que compreende a universalidade desde um lugar, desde nosso próprio chão, onde o corpo é produtor e fonte de conhecimento" (MACHADO, 2009, p.3).

Com isto em mente, proponho, a partir da obra de Rosana Paulino, um arquivo-coleção: uma constelação de tempos que alimentam a memória. Deste modo, trata-se de um arquivo que não se dirige obsessivamente para o futuro movido por um ímpeto destrutivo de repetição, acumulação e suplementação. Nem tampouco um arquivo que seja sustentado pela lei. Um arquivo nagô seria um arquivo guiado pela Arkhé como princípio geral, começo eterno. Um arquivo que retorna ao princípio, ao corpo, à cozinha, para reconhecer ausências e nutrir, não para catalogar, registrar e fixar. É assim um arquivo que abre e cria a temporalidade tanto para o passado quanto para o futuro ou presente. Como sugere o aforismo, Exu cria seu próprio tempo. Por que não afirmar, então, que o arquivo também elabora seu próprio tempo pelas mãos do curador?

Seguindo a tradição nagô, destacamos que essa temporalidade é uma temporalidade mediada pela experiência humana, mais especificamente na forma da narrativa. Nos termos de Sodré, "numa cultura de Arkhé, nada 
realmente se determina, mas tudo se narra ou se conta" (2017, p.432, grifos meus). Ou seja, a narrativa, ou no nosso caso, de forma expandida, a arte visual e a expressão dos corpos em movimento, são elementos constitutivos do tempo. Nessa mesma linha, o professor e babalorixá Agenor Miranda ensina que na tradição lorubá "só se pode justificar um fato com uma história analógica" (2007, p. 29).

Isso aponta para uma circularidade na noção de tempo, à medida que a narração é ao mesmo tempo reiteração, ratificação e elaboração de uma experiência. Reiteração porque evoca um "fato", logo, algo já passado que é reafirmado; ratificação porque é a história que o "justifica"; e elabora uma experiência porque a "história" se dá como elemento de mediação de uma relação. Em outras palavras, a história está implicada na relação presente, e é por ela reelaborada. A cada nova história contada o presente se atualiza.

A necessidade da elaboração da história a partir de outros pontos de vista, que contem outras histórias, encontra eco na tradição afro-diaspórica nas Américas. Como lembra Glissant, diferentemente do migrante branco, que atravessou o Atlântico no Mayflower e levou seus modos, costumes (e propriedades) para parte da América do Norte, parte da América Latina e o Caribe foram fundados pelo que o autor descreve como "migrante nu", aqueles forçados a deixar a África em direção às Américas (2008).

Na travessia do Atlântico, desnudados de vínculos territoriais e afetivos, e forçados a se comunicar, os migrantes precisaram elaborar um sistema ético baseado na diversidade. Um código aberto, capaz de abrigar a todos, compartilhando memórias, valores e descobrindo uma ética a partir da mais radical contingência, dado que estavam completamente desterritorializados (GLISSANT, 2005; 2008). No continente Americano, com vestígios de suas línguas, culturas e memórias de seus deuses, esse migrante reconstruiu sua identidade. Uma identidade profundamente afetada por uma experiência radical de despossessão (GLISSANT, 2008, p.87). Sob um ponto de vista geográfico, o autor destaca que esse é o tipo de migração que marca territórios que vão do sul dos Estados Unidos ao Nordeste do Brasil. Essa, para Glissant, é a América "cujos povos são resultado da crioulização" (2008, p.83).

Nesse sentido, um arquivo nagô é o reverso do arquivo dos catálogos, museus e grandes bibliotecas. É o arquivo do "migrante nu". Movimento e corpo, em oposição à lugar e lei, são as condições de possibilidade desta proposta. Afinal, os corpos, ajuntados nos porões dos navios, são pontos de 
origem e condição de possibilidade deste arquivo diaspórico. Um arquivo marcado pela violência, pela resistência e pela alegria como potência vital.

Pensar um arquivo nagô, pois, implica em abrir os olhos para a genealogia da cultura brasileira, formada por relações indesejadas e suas contingências. É um arquivo malê-iorubá-ameríndio. É também um arquivo português pela contramão. O arquivo, como o álbum de família que resgata a história ancestral, prática contínua, construção e cultivo, curadoria de imagens e de relações. Ali, a presença das imagens não é ditada pelas regras de uma figura patriarcal e normativa, como o arconte grego. Antes, as imagens transitam em razão de dinâmicas estritamente afetivas, familiares, corpóreas e, mesmo, banais. Isto, contudo, não diminui a importância do arquivo, não torna sua acumulação menos profunda, sua relação com o tempo menos sagrada. Nessa medida, arquivo nagô, e álbum de família, se expandem em múltiplas direções, abrindo o corpo do tempo aos que nele se implicam.

\section{Rosana Paulino e agulha do real}

Partindo da pesquisa de fotos que recompõem a genealogia familiar, se inicia a trajetória artística de Rosana Paulino. Em entrevista para a TV Brasil, por ocasião da exposição A costura da memória, a autora afirma que, em seu amadurecimento como artista, percebeu que não poderia apenas pensar o país “do ponto onde eu estou [...] e vou atrás de outras memórias, e aí entra a memória do grupo étnico". Na declaração, nota-se o imbricamento de pontos fundamentais para esta reflexão.

Primeiro, cabe destacar o interesse da artista em se posicionar a partir da condição de mulher negra. Esse posicionamento é sublinhado pela observação a respeito do lugar onde ela ocupa o mundo, sua família e seus afetos. Trata-se, pois, de uma busca pessoal, mas Rosana não caminha sozinha. Resgatando sua trajetória familiar, ela deseja pensar "o Brasil". Assim, a posição de indivíduo é relativizada pela busca de uma "memória do grupo étnico". Paulino pensa o país a partir da perspectiva de um grupo estratégico para a formação da nação. Logo, há um compromisso com a pesquisa e a memória coletiva (ANTONACCI, 2014).

Seguindo esse caminho, a artista se une a uma tradição de mulheres negras que contribuíram para reelaborar criticamente as questões como raça e gênero no país. Como afirma Leda Martins, a literatura produzida por escritoras negras no Brasil constitui-se em “[...] um instrumento e um locus 
privilegiado para uma potente e persistente rasura, descontinuidade e desconstrução [...]" (MARTINS, 2007, p.64, grifos meus).

Nesse sentido, outro elemento fundamental do trabalho de Paulino é o respeito às imagens em sua dimensão autônoma, de entidades da memória social. No esforço para recuperar e reelaborar a memória coletiva a partir do ponto de vista da mulher negra, a obra de Paulino se une a uma rica tradição literária. Não por acaso, Leda Martins afirma que a "retórica de retalhos" produzida pelas escritoras negras é elaborada "[...] de restos e resíduos do cotidiano, alinhavados numa partitura que prima pela justaposição de contrastes, cores, desenhos e traçados aparentemente destoantes e desalinhados, que se conformam numa uniformidade assimétrica [...]" (2007, p.71, grifos no original).

Seguindo sua vocação para a "rasura", Paulino reconhece gostar de "[...] trabaIhar com a foto já feita, porque ela traz um afeto muito grande" (ANTONACCI, 2014, grifos meus). Ali, fica claro que, para a artista, a imagem, mais que insumo para sua produção, é um ator com o qual se relaciona. A declaração também evidencia a importância do objeto histórico no trabalho da autora, que busca não apenas o arquivo, mas também a dimensão afetiva que o acompanha.

A fotografia, assim, aparece como um registro de outro tempo e como uma manifestação do presente cuja expressão extrapola a vontade da artista. Neste sentido, traçamos o contraste entre o registro como parte de uma categoria e o registro que é, ele próprio, a categoria. Na obra de Paulino não há uma "escravidão" genérica. Há marcas da escravidão em corpos distintos, sendo cada um deles responsável por um relato parcial, um testemunho.
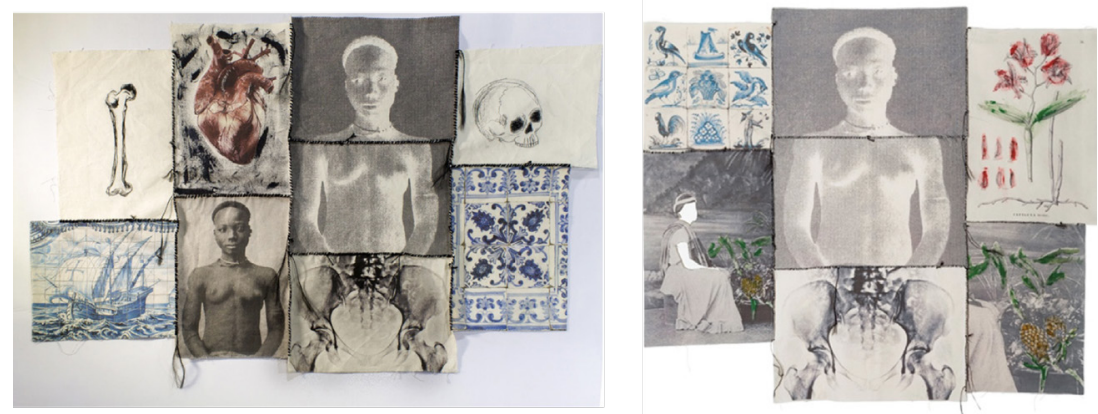

Figura 1. Obras Rosana Paulino: Sem título, à esquerda; Paraíso Tropical?, à direita. Fonte: Acervo Rosana Paulino, online'. 
Ligando elementos internos de cada exposição, e exposições entre si, está presente a preocupação em aproximar tempos e espaços fraturados. Essas ligações ficam evidentes em diversas obras da artista. No quadro anterior (Fig.1) é possível observar o desdobramento de temas caros à autora em duas composições. Em Paraíso tropical (à direita), ilustrações da vegetação brasileira se coadunam com a imagem de uma mulher negra de busto desnudo, situada acima de uma imagem que remete a um raio-X de ossos da bacia. Ao justapor tais imagens Paulino usa o arquivo contra ele mesmo. A heterogeneidade das imagens-documento se harmoniza ao apontar para a univocidade do discurso. A exposição reproduz traços do imaginário tecnocientífico da empreitada colonial e os coloca lado a lado com a retórica da salvação. Constitui-se assim um mosaico crítico ao período colonial que se espraia até os dias atuais.

Em ambas as composições, contudo, as imagens parecem não se conformar com o arranjo. A figura feminina, mesmo sob efeito de tecnologias desumanizantes, como a escravidão e o raio-x, mantém um olhar penetrante e inquisitivo. O corpo-imagem se recusa a figurar como objeto e se ergue como elemento central na composição. Há uma vida na imagem que se desdobra nas obras.

Ainda relevante é o jogo de repetição e diferença estabelecido pela permanência da figura da jovem de busto desnudo em diferentes composições. No trânsito de paisagens, a dignidade daquele corpo feminino resiste aos mais violentos processos de objetificação. Um corpo que continua na imagem e que extrapola a constelação em que está inserida para reivindicar sua própria história. Ali, mais que a leitura da artista, é relevante pensar no testemunho da imagem. O que diz aquele corpo ereto, de olhar firme que, ao se dirigir ao fotógrafo, viaja no tempo com o testemunho de sua história? Uma história da escravidão, do feminino, do Brasil, também uma história única. No corpo-imagem, a experiência de um país emerge não como síntese, mas como potência.

Além do feminino, a metáfora da costura e as ligações transatlânticas são uma constante na obra de Paulino, e se evidenciam nos títulos de suas exposições, como Costura da Memória, e em Atlântico Vermelho ou Tecido Social. Ali, Paulino cria os tecidos que irá perfurar, ligar, pendurar, expor. Ao materializar esses elementos, o debate sobre um país cindido, uma memória cultural amputada, violências históricas: tudo isso é materializado. Essa 
matéria, entretanto, constitui um corpo-multidão. Como se admitisse a impossibilidade de descrever, a artista propõe constelações, associações abertas ao observador. Os quadros formados por Paulino elencam multiplicidades possíveis.

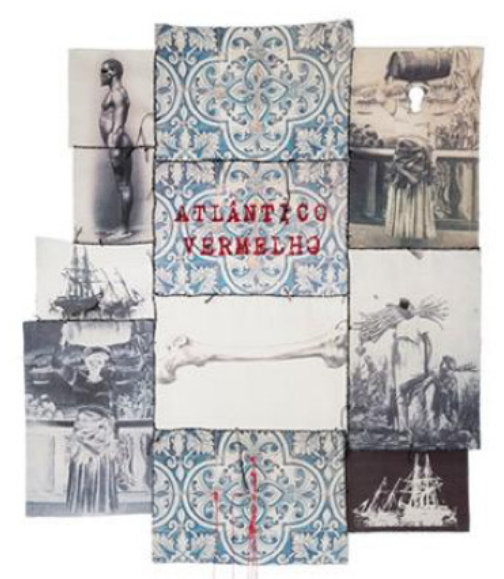

Figura 2. Rosana Paulino, Atlântico Vermelho. Fonte: Acervo Rosana Paulino, online ${ }^{2}$.

Numa espécie de abertura de caminhos que levou à elaboração de Costura da Memória, a exposição anterior, Atlântico Vermelho (2016), aciona a memória cultural brasileira sob o ponto de vista do povo negro. Esta, aliás, juntamente com o corpo feminino, é uma preocupação que atravessa a trajetória da artista.

Em Atlântico Vermelho, Paulino evoca a imagem de um Atlântico negro, sugerida por Paul Gilroy (1993), e sublinha que os movimentos que ligam a África, Europa e Américas são tingidos pela violência. A monumentalidade do oceano é tingida pelo sangue negro e serve de espelho para o genocídio indígena. Assim, as imagens de Paulino convocam a episteme colonial ao desafiar um repertório digno de museus de antropologia e história natural. Não por acaso, uma das obras expostas em Atlântico Vermelho é o livro História Natural?, que questiona os paradigmas científicos em torno da fundação do Brasil. 
Seguindo esse fio, evocamos dois quadros de tecido intervalados pelo perfil de uma mulher negra que se confunde com um azulejo português levemente manchado de vermelho. Como em um livro, as páginas laterais trazem apenas a frase "a salvação das almas?", ao passo que a página central apresenta o corpo ao qual se nega uma alma. Como uma interrogação reproduzida repetidamente sobre o tecido amarelado, a pergunta ecoa incomodamente. A salvação das almas? A cada nova versão, a frase ganha modulações decorrentes da mudança de fonte, de posição no tecido, mas sobretudo decorrente de seu próprio eco. A frase vibra, ao ecoar no corpo do observador. Os três pedaços de pano rotos são ligados por uma linha negra costurada à mão. No relevo da costura se destaca o entrelaçamento entre corpos e discurso. No corpo daquele que lê em voz alta a dor de muitas gerações encontra eco.

A técnica da costura, que pressupõe a criação e preenchimento de fissuras no tecido, é estratégica para a formulação do problema. Paulino cria um arquivo pelo rearranjo de aproximações forçadas por meio do poder colonial. Desta vez, o arranjo é feito com a delicadeza de uma crítica mordaz que não precisa se impor. Uma crítica que consiste fundamentalmente no olhar e no toque, que aproximam elementos violentos. Mais que isto, a riqueza tátil das obras requer o engajamento corporal dos que visitam a exposição.

Nesse exercício, Rosana Paulino resgata e reorganiza o passado brasileiro através de costuras em tecido. Parece oferecer ao público a possibilidade de um arquivo costurado, sugerir que memórias são ligadas por uma linha frágil, mas persistente. Na composição de quadros ligados pela linha preta, formas de grande carga afetiva se organizam em uma espécie de relato alternativo da colonização brasileira. Paulino recompõe a história, mas não se exime de interferir criticamente. O corpo da artista está presente na obra. A arquivista assume sua prótese tornando-a objeto visível, exposto ao debate.

Nesse movimento, a artista põe em prática a proposição de Donna Haraway, para quem a "objetividade feminista significa, pura e simplesmente, [reconhecer] conhecimentos situados" (HARAWAY, 1988, p.581). Ou seja, tanto em Paulino quanto em Haraway, fica clara a importância do pensamento localizado geo-historicamente, mas também pensamento-ação a partir de um corpo determinado.

Essa relação é vital para uma história em fluxo. No arquivo vivo, os azulejos portugueses estão manchados com sangue que, efetivamente, marcam a herança cultural portuguesa. Não se trata propriamente de um julgamento, 
mas constatação. Os azulejos continuam presentes em sua potência e beleza. O que Paulino faz, ao revelar as manchas de sangue é desvelar uma outra camada do objeto em sua existência simbólica. Ou seria material? Quantos azulejos e igrejas terão sido manchados pelo sangue de pessoas negras?

Na pergunta sobre A salvação das almas ecoa o discurso civilizatório da cristandade europeia. A questão, porém, não vem sozinha. É acompanhada da paisagem que reforça a materialidade, e a gravidade, do enunciado. Salvação das almas? O discurso, portanto, é também paisagem. Bem como lembrança é presença, e o copo vazio é um copo cheio de ar.

Paulino revela a colonização e escravidão no Brasil como um renascimento às avessas. Afinal, foram os recursos naturais, e vidas, extraídos no Brasil que subsidiaram o desenvolvimento do capitalismo mercantil na Europa. Capitalismo este que viria a inundar museus e arquivos coloniais. Marcado por um continuado genocídio dos povos originários que se somou à escravidão e genocídio do povo negro, o Brasil nasceu como país em um recrudescimento de suas culturas formadoras. Nas imagens, esse processo é poeticamente abordado por meio de costuras que ligam imagens de azulejos coloniais a corpos negros, navios portugueses, estudos da flora Brasileira e imagens de ossos.

Em suma, um longo aparato discursivo aparelhado pela ciência, pela arte e pela religião. O delírio português de civilização tropical é retratado ali como lembrança febril dos corpos emudecidos pelo aparato cultural. Mais que resgatar o passado, contudo, Paulino opera um processo de reinterpretação da cultura nacional. Esse processo pode ser ilustrado nos termos de Sontag, para quem a interpretação pode funcionar tanto como um processo "reacionário" como uma forma de "revisar, transvalorar, e escapar de ‘um passado morto"' (2013, p.21).

No uso de linha e agulha, a artista realiza uma sutura simbólica do tecido social brasileiro ${ }^{3}$ em uma reinterpretação que revisa o passado morto-vivo da colonização. As obras parecem revelar que não há cura sem diagnóstico. Não há sutura do tecido que não se percebe trapo. A cura pois, não é estritamente o processo de tratamento da medicina moderna. Na etimologia latina, a palavra cura se refere a um processo de cuidado, de responsabilidade sobre o vulnerável, de afeto. Por outro lado, apesar da amarração 
(sutura) que enfatiza a dimensão violenta do encontro, a linha é elemento de mediação e fronteira entre partes.

Segundo esse raciocínio, Rosana Paulino exerce uma performance de cuidado da memória nacional. Sendo mulher negra, ela ocupa uma posição privilegiada para pensar a história do povo negro na diáspora, e a história deste país negro sob máscaras brancas. Nas linhas da artista, guiadas pela agulha perfurante, a realidade do tecido é penetrada pelo tempo. A costura liga tempos e corpos, mas não sem antes lembrar dos encontros e permanências que são coercitivos.

Nunca estabilizado, o tempo segue seu curso, criando o novo com rasgos do passado, como os painéis de Rosana ao justapor o corpo africano escravizado à anatomia do indígena e os azulejos portugueses. Os corpos e objetos se justapõem, coexistindo em uma mesma imagem por força da intenção humana. O tempo costura geografias, corpos e coisas. E Paulino costura o tempo com formas sensíveis.

É a memória transformada pelos encontros violentos entre diversas etnias de origem africana nos navios portugueses financiados por bancos ingleses e sangue indígena. Na obra da artista, é a linha que coze as relações e que aproxima corpos de paisagens, história oficial de memória individual e coletiva. A linha é um instrumento do tempo em movimento.

\section{Considerações finais}

Este artigo realiza um percurso que cruza ideias de distintos intelectuais diaspóricos em três etapas incrementais, ainda que desiguais. Em comum, os atores que contribuem para esta análise apresentam marcas da diáspora e o tensionamento com a memória social e o território em que se inserem. A ênfase, contudo, recairá sobre a questão da diáspora africana no Brasil com vistas a sua articulação regional (nas Américas).

Abrindo o trabalho, apresentamos uma reflexão preliminar acerca da noção de arquivo na leitura Derridiana da obra de Freud em Mal de Arquivo: Uma impressão freudiana (DERRIDA, [1995] 2001). De maneira sintomática, analisando Mal de Arquivo, Joel Birman nota que "Freud não conseguiu efetivamente se desembaraçar do princípio arcôntico da autoridade na sua existência" (2008, p.121). Aqui, retomamos a provocação de Derrida sobre o "mal de arquivo" tendo em vista a curadoria como exercício de cura. 
Assim, encontramos a imagem dos manifestantes do movimento Black Lives Matter derrubando a estátua de um comerciante de escravos. Esse segundo movimento, aponta para a necessidade de se repensar as formas de lembrança, arquivamento, princípio, ordem e símbolo. Na imagem de Reid encontramos um indício de um tempo atualizável, onde a lembrança se transforma para seguir viva e a atuante no mundo. Não há repetição nesta atualização. Há emergência de atores "esquecidos" pela história oficial.

Movido por essas provocações, o trabalho cruza o Atlântico e encontra como esteio teórico/empírico pensamento e sensibilidades afro-diaspóricas de Muniz Sodré e Rosana Paulino. As obras de Sodré e Paulino, em seus diferentes suportes, são pontos de inflexão para uma discussão que visa reconfigurar os problemas da memória e do arquivo. Com Paulino, as imagens ganham contornos de tragédia e encantamento ${ }^{4}$. Embora marcadamente trágicas, as imagens possuem também uma potência vital. Encarnam os males da colonização territorial e epistêmica, mas também evocam uma história de lutas e indignação. São, sobretudo, testemunhos de uma cultura que continuou, apesar de tudo. Neste ponto, a dimensão da autoria é fundamental. Afinal, as imagens são criadas pelas mãos de Paulino, mulher negra, que toma para si a responsabilidade de mais um resgate da memória africana no Brasil.

Novamente evocamos a questão da Arkhé como começo e comando. Ambas as noções aqui são manejadas pelo tempo da artista, pelo tempo histórico, pelo tempo da própria obra na sua existência no mundo. Observa-se aqui um outro olhar, a mesma história, reformada a contrapelo.

Entrecortado corpos e paisagens, Rosana Paulino aponta para a necessidade de produzir relatos fissurados, de injunções visíveis. Ao tomar posições nas relações sociais e políticas, o sujeito revela compulsoriamente a dimensão desigual das relações étnicas e culturais, sem com isto abrir mão de uma reflexão sobre si e o outro. Nessa medida, ao compor imagens da relação, sobretudo da relação entre corpo e paisagem, a artista indica que é preciso pensar o corpo no mundo, porque "sujeito" é aquele que ocupa espaços, corpos e tempos.

Ambas as mulheres citadas operam na produção de temporalidades ligadas ao corpo, mas não limitadas por ele. A exemplo do pensamento feminista

\footnotetext{
4 Aqui usamos o termo em consonância com Simas e Rufino, para quem "o encantado é aquele que obteve a experiência de atravessar o tempo e se transmutar em diferentes expressões da natureza" (SIMAS; RUFINO, s.n., 2020). É também relevante que Sontag (2013, p.14) sublinhe que "as primeiras experiências artísticas devem ter sido encantadas, mágicas [...] instrumento de um ritual".
} 
proposto por Haraway, são arquivos vivos, que não têm a "pretensão de eternidade ou onipotência" (1988, p. 580), são perspectivas, e documentos, parciais. Como proposição ética, o arquivo nagô toma a corporeidade e suas associações mundanas como condição para a produção de arquivos contrainstuticionais. Ao ligar rasgos traumáticos da própria história, enquanto ser coletivo, Paulino liga-se com o tempo histórico. Igualmente, o decepar e afogar estátuas, os manifestantes espalhados pelo mundo reivindicam um arquivo ligado ao desejo coletivo, negando ao Estado o monopólio da história. Nesses gestos, reconhecemos a potência de um arquivo movido pela potência de lembrança, contra o esquecimento.

Diego Granja do Amaral é professor da Uninassau. É doutor em comunicação pela Universidade Federal Fluminense e pela Eberhard Karls Universität Tübingen (Estudos do Sul Global). É pesquisador nos projetos PRINT e PROBAL, em parcerias entre UFF e a Universidade de Tübingen (EKUT).

diegoamaral000@gmail.com

\section{Referências}

ANTONACCI, C. Rosana Paulino. [Entrevista]. [Entrevista concedida a] Célia Maria Antonacci. São Paulo: 2014.

BIRMAN, J. Arquivo e Mal de Arquivo: Uma leitura de Derrida sobre Freud. In: Natureza Humana v.10 n.1., 2008.

DELEUZE, G., GUATTARI, F. O que é a filosofia?. São Paulo: Editora 34, 1991.

DERRIDA, J. Mal de arquivo: uma impressão freudiana. Rio de Janeiro: Relume Dumará, 2001.

Archive fever: A Freudian impression. Diacritics 25.2 (1995): 9-63.

DIAS, J. Dos “Nàgó" da Bahia aos "Pọ́rtúgérè" de Lisboa: Um olhar sobre identidade e religião em diáspora. Cadernos de Estudos Africanos, 25 | 2013. Disponível em: <http://journals. openedition.org/cea/904>. Acesso em: 9 nov. 2020. DOI: 10.4000/cea.904

GLISSANT, É. Introdução a uma poética da diversidade. Juiz de fora: UFJF, 2005. pp.81-89.

.Creolization in the Making of the Americas. Caribbean Quarterly, v.54 n.1/2, 2008, 
GILROY, P. O Atlântico Negro como contracultura da modernidade. Rio de Janeiro: Editora 34,1993.

GOGARTY, C. Priti Patel says toppling of Colston statue is 'utterly disgraceful' - but Piers Morgan hits back. In: Bristol Post, jun. 2020. Disponível em: <https://www.bristolpost. co.uk/news/bristol-news/priti-patel-says-toppling-colston-4202300>. Acesso em 15 jan. 2021.

HARAWAY, D. Situated Knowledges: The Science Question in Feminism and the Privilege of Partial Perspective. In: Feminist Studies, V. 14, N. 3 (Outono, 1988), pp. 575-599.

MACHADO, A. F. ODUS: Filosofia Africana para uma metodologia afrorreferenciada. In: Voluntas: Revista Internacional de Filosofia, v.10. Ed. Especial, 2019. DOI: 10.5902/2179378639952

. Ancestralidade e encantamento como inspirações formativas: filosofia africana mediando a história e cultura africana e afro-brasileira. Dissertação (mestrado) - Universidade Federal da Bahia. Faculdade de Educação, Salvador, 2014.

MARTINS, Leda. "A fina lâmina da palavra". In: O Eixo e a Roda: revista de literatura brasileira v.15, 2007.

MBEMBE, A. The Power of the Archive and its Limits. Refiguring the archive. Springer, Dordrecht, 2002.

MEIRELLES, M. Artistas veem derrubada de estátuas como resgate e não apagamento de figuras. In: Folha de São Paulo, 5 jun. 2020. Disponível em: <https://www1.folha.uol. com.br/ilustrada/2020/06/artistas-veem-derrubada-de-estatuas-como-resgate-e-nao-apagamento-de-figuras.shtml>. Acesso em: 15 jan. 2021.

OLUSOGA, D. The toppling of Edward Colston's statue is not an attack on history. It is history. In: The Guardian, jun. 2020. Disponível em <https://www.theguardian.com/ commentisfree/2020/jun/08/edward-colston-statue-history-slave-trader-bristol-protest>. Acesso em 15 jan. 2021.

PAULINO, Rosana. A Salvação das almas? Impressão digital sobre tecido e costura, 2017. Disponível em <https://www.rosanapaulino.com.br/>, acesso em jul. 2020.

. Atlântico Vermelho, Padrão dos Descobrimentos. Exposição. Lisboa: EGEAC, 2016.

. Atlântico Vermelho. Impressão digital sobre tecido, recorte e costura. Disponível em <https://www.rosanapaulino.com.br/>, acesso em 20 jul. 2020.

Sem título. Impressão sobre tecido, ponta seca e costura, 2016. Disponível em <https://www.rosanapaulino.com.br/>, acesso em 20 jul. 2020.

SIMAS, L.; RUFINO, L. Encantamento: Sobre política de vida. Rio de Janeiro: Mórula Editorial, 2020.

SAID, E. W. "Invention, memory, and place". Critical inquiry 26.2 (2000): 175-192. 
SODRÉ, M. Pensar nagô. Petrópolis: Editora Vozes Limitada, 2017.

SONTAG, S. Against interpretation and other essays. Nova lorque: Picador, [1964] 2013.

Artigo recebido em 01/10/2020 e aprovado em 11/02/2021. 